\title{
Smart Interactive Learning Measures for the Modern Education System
}

\author{
Muhammad Shahzad Nazir \\ Faculty of Automation, Huaiyin Institute of Technology, Huai'an, 223003, China \\ Email: msn_bhutta88@yahoo.com
}

\author{
Article History \\ Received: October 15, 2020 \\ Revised: November 22, 2020 \\ Accepted: November 26, 2020 \\ Published: November 28, 2020
}

\begin{abstract}
Educational needs are of paramount importance for educational institutions. We proposed a synergistic framework for combining the key elements of teaching and learning, with a flow theory approach that can induce the overall learning efficacy with an added value of sustaining the smart teaching and training environment. The given framework has various applications in the realms of technology, communication, and learning to help students adjust their learning needs and resolve any issues within the school system. There are positive outcomes to the proposed framework of minimal learning requirements, due to a more confident learning environment, that can allow for more advancement and academic success. Students cognitive ability and ability to learn can be improved via constant monitoring and analyzing of the student's performance with software and technology (IoT). Figuring out how to build Internet of Things applications for the various student levels in one classroom is a challenging issue. Our aim is to assist user to appreciate the aptitude, adapt, and use technologies like artificial Intelligence to produce fruitful learning objectives.
\end{abstract}

Keywords: Smart education; Smart tools; E-Learning; Learning efficacy; Internet of things AI.

\section{Introduction}

Smart education and computer-based learning techniques are needed to support students transition from traditional classrooms to the new web-based learning world [1]. Interactive touch screens and digital displays are used to provide some sort of educational strategy. Classroom settings are a special kind of education for learners (students). It can allow one to touch, select, drag, and reorganize or manipulate the given information on the screen [2]. Some software programs and hardware tools have been designed or developed by experts for helping students with required support materials, and for maintaining classroom activities in an interactive and sophisticated manner $[1,2]$. Broadly speaking, the intelligent interactive system comprises three primary or major gears, e.g., (1) intelligent applications for running the activities, e.g., software programs, (2) cloud-enriched analysis systems, and (3) intelligent interactive device, e.g., touch screens, digital boards, or smartwatch Considering that there are lots of kids nowadays are gaining more and more knowledge from smart electronic devices, traditional teaching models are not suitable any more. It may have difficulty to educate the growing youth population. We need innovative educational methods, such as smart interactive education, for our modern society [3]. It is evident from existing literature that several universities and institutions around the world have implemented interactive learning measures in the classroom for a variety of ages and levels of education. They have studied a low-cost interactive writing board for primary education through the use of augmented reality markers. Even engineering students may present difficulties to understand complex topics in Math and engineering. Here, we try to provide some graphical help from several perspectives [4].

A study presented a collection of Chinese Simplified characters for interaction through an Interactive Writing Board (IWB) [5]. The obtained study illustrated that the system improved motivation and learning skills among students. Teachers have devised a smart combination (mobile phone) mobile app Socrative and smartphones to reach students' minds with active physics learning. Xavier Fischer proposes an interactive educational system from different perspectives. Human requirements can help computing engineers improve their design process by incorporating user needs into their engineering design [5].

\section{In Smart Education, What is Smart?}

There is no actual definition of Smart Learning. However, there is a diverse range of definitions. Generally speaking, "smart education" is a learning trend that allows and facilitates learning in the modern time. The English definition of smart can be grouped as self-directed, adaptive, enriched, and technological. Within the past few years, there has been increased interest in the concept of "modern learning". From the educational perspective, "smart education" usually means, "interactive," "scalable" and "multi-based." It is necessary to provide classroom activities suitable for the intelligent machines in today's fast-paced world. Authors describe the benefits of ed tech to various education institutions. Smart Pedagogy can be used to create holes in the dumbed-down education system. this 
research highlights the different opportunities for online problem-based education and the smart pedagogic collaborative cloud. Literature evidence from many studies has shown that the digital learning environment contributes significantly to the students' disposition, personality, temperament, and creativity of university students. These days, science and technology are now helping to create more intelligent and healthier learning environments. It supports learners with new learning techniques, technologies, processes, and strategies. The purpose of education in Singapore is to equip students to tackle issues that they will find in modern society. This is to help future learners have an abundant learning and living scenario. This unique subjective approach further permits the student to test his or her potential skills, enhancing his or her total training. The high-level standards of English in the Smart English learning environments are in line with these learning environments. The smart classroom characteristic are presented in Figure 1.

Figure-1. The smart classroom characteristic

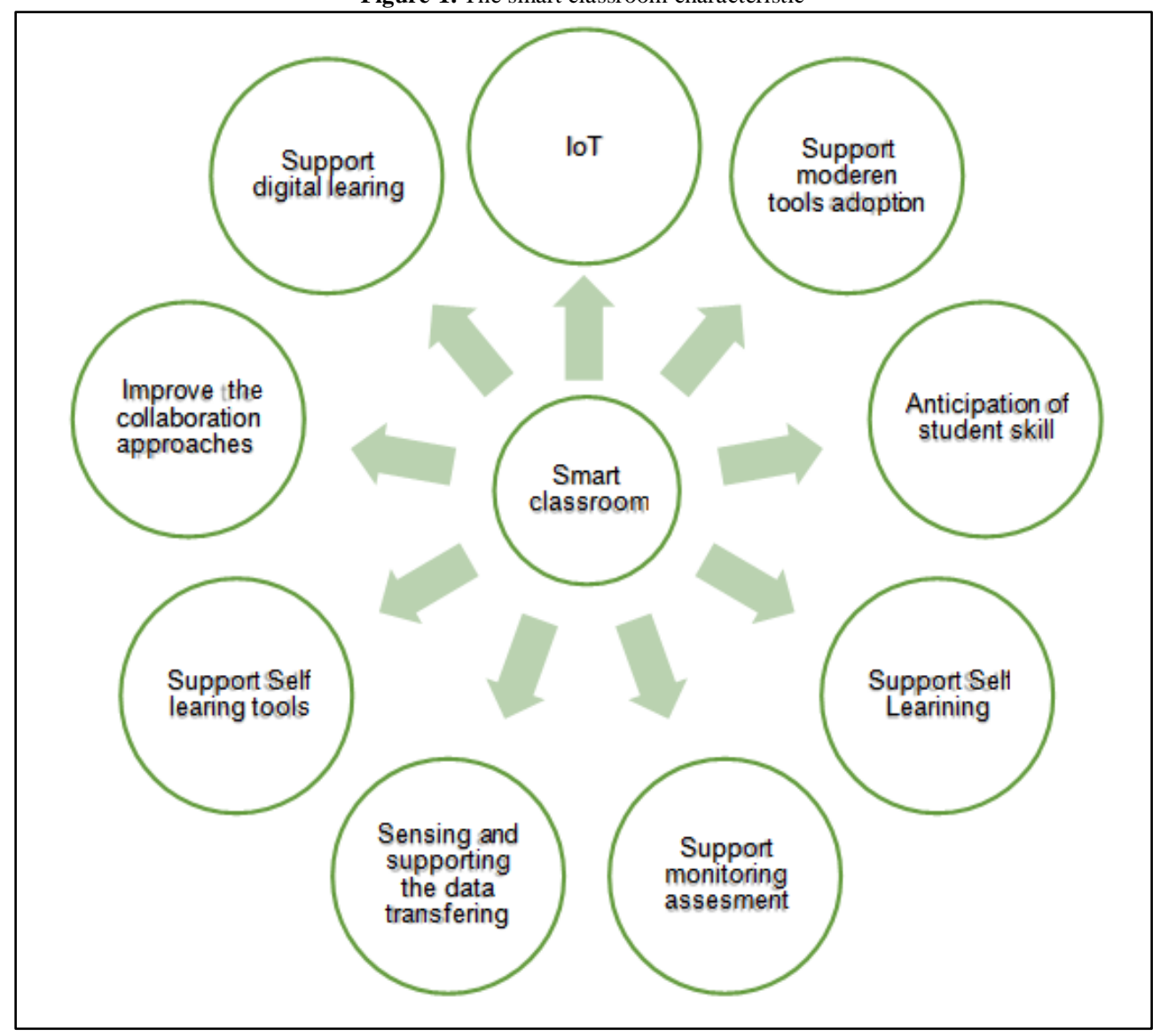

\section{Key Challenges and AI Framework}

Although technology-based digital learning has become more mature with IoT. The entire learning environment needs to be integrated to allow for "smart learning" [6]. However, there are some key issues to address to give recognition to the "smart learning" conception. The learning behaviour analysis and learning tracking were either neglected or even covered very little in the learning systems [3]. Appropriate consideration of the learners learning behaviour and learning patterns can further inform educational programs. The integration of real and virtual within a single learning interface can help the academic world to develop highly useful and creative tools and strategies for conducting learning activities [7]. Besides the learner's attitudes, the performance of learning, attributes of learning, and evaluations of the learner's attitude should be considered. By taking into account knowledge performance, knowledge attributes, and opinion in a smart learning environment, the review can be conducted from various aspects. There are many sorts of ability which show that students are good in their way. Artificial Intelligence (AI) is a technology that enables a machine to imitate human behaviour. It is an AI subset which allows a machine to learn from past data without programming explicitly. The goal of AI is to make a computer system that is smart like humans. An illustration of how AI can advance the present-day higher education is depicted in Figure 2. 


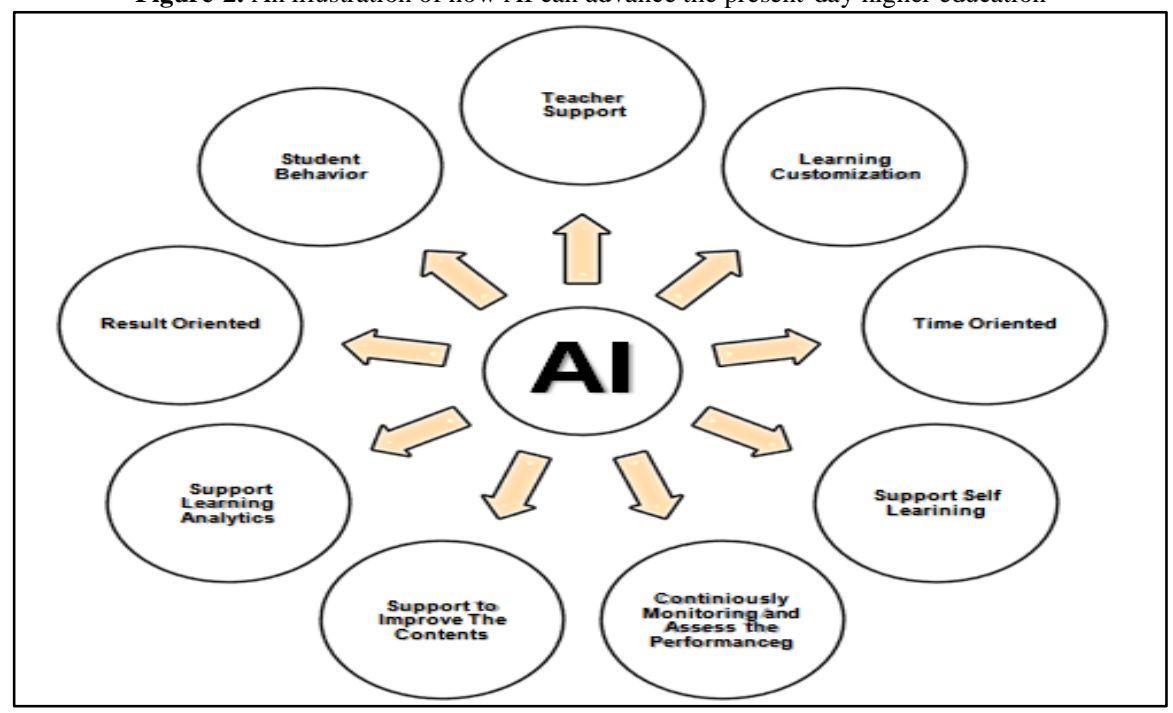

There are a variety of great cognitive control apps. They are still engaged in imaginative cognitive environments. The technology-based learning and assessment (TBLA) approach must be re-assessed to strengthen the existing educational model. Innovation in assessment software will address pedagogical issues. A problem-based learning (PBL) instructional approach can benefit smart literacy learning in the twenty-first century. Because of the overhead spotlights, creating smart learning environments with existing is a challenging task.

\section{Author's Opinion}

To build a stronger relationship between the online and offline classes, it is necessary to design better online learning environments as well as proactively implement the analytics tools and technology that will help teachers learn every time they teach. It is hoped such integrated formal and informal approaches can provide an impressive helping hand for the students because it compliments their inherent innate teaching abilities. The study did not address the use of smart learning management systems. This study mentioned the qualities and needs of a learning management system framework. A learner profile will focus on students characteristics, learning objects, organizational and collaborative skills etc.

Tools and modules should be based on the big data approach and analytics system that integrates the real-time data regarding learners location and historical data. Besides, there are many other learning environments which require both real and virtual environments. One of which includes social awareness, computer vision, intelligent interaction, and intelligent management tool for online learning methods. Teachers can have the most efficient computer devices for E-learning and computer based teaching. Taking into account the various aspects on learners' behaviour and learning patterns, as well as the in-depth understanding of both, could aid policymakers, academic staff and instructors to create more robust and efficient, flexible and effective learning tools and strategies to support the 21st century smart learning framework. A monitoring and scrutinizing platform could concentrate on a specific student and help individualize the educational mode and assignment self-regulated learning styles for the learners. This lesson plan consists of information that is appropriate for the learner and the learner's concerns. Using an example, the case of IoT is outlined. This has a significant effect on the decision making process in the educational sector to fulfil the rising market need and demand. There is potential to disrupt a variety of economic and societal niches (e.g., health care, logistics, manufacturing, health care, security, transportation). There will be a "paradigm shift in socio-economic model" because of IoT. The IoT is getting quite complex and needs a deeper understanding. Furthermore, it is not completely clear where and how the IoT will develop in the future.

\section{Acknowledgements}

The authors would like to acknowledge the technical support of Huaiyin Institute of Technology, in the production of this work. The library services at Huaiyin Institute of Technology, are thankfully acknowledged for providing the literature sources.

\section{Conflict of Interest}

The listed author(s) declare no conflict of interest in any capacity, including competing or financial.

\section{References}

[1] Uskov, V. L., 2017. "Smart pedagogy for smart universities." In International Conference on Smart Education and Smart E-Learning, Springer. 
[2] Chen, N. S., Cheng, I. L., and Chew, S. W., 2016. "Evolution is not enough: Revolutionizing current learning environments to smart learning environments." International Journal of Artificial Intelligence in Education, vol. 26, pp. 561-581.

[3] Štuikys, V., 2015. Smart learning objects for smart education in computer science. Springer.

[4] Bimba, A. T., 2017. "Adaptive feedback in computer-based learning environments: a review." Adaptive Behavior, vol. 25, pp. 217-234.

[5] Hsueh, S. L., 2008. "An investigation of the technological, pedagogical and content knowledge framework in successful Chinese language classrooms, Theses and Dissertations." Theses and Dissertations, Available: https://scholarsarchive.byu.edu/etd/1618

[6] Hoel, T. and Mason, J., 2018. "Standards for smart education-towards a development framework." Smart Learning Environments, vol. 5, pp. 1-25.

[7] Al-Emran, M. and Shaalan, K., 2017. "Academics' awareness towards mobile learning in Oman." International Journal of Computing and Digital Systems, vol. 6, pp. 45-50. 